Revista

\title{
Multi-Ensayos
}

Vol. 7, núm. 13

ISSN: 2412-3285

https://multiensayos.unan.edu.ni

DOI: https://doi.org/10.5377/multiensayos.v7i13.10752

\section{Entre rezos, festejos y disputas por un santo esqueleto}

\section{Among prayers, celebrations and disputes for a holy skeleton}

\author{
Ángel Alejandro Gutiérrez Portillo
}

Recibido: 14 de octubre de 2020. Aceptado: 17 de Noviembre de 2020

\section{RESUMEN}

Este es un estudio religioso que versa sobre la religiosidad popular que se da en torno al culto a San Pascual Bailón en Tuxtla Gutiérrez, Chiapas, México. La particularidad de este santo radica en que su representación es un esqueleto de madera ataviado con una túnica franciscana que permanece en un carretón-ataúd, el cual es venerado por miles de personas en diversas latitudes del Estado. En ese sentido, el objetivo del trabajo es describir y analizar cómo a partir de las transformaciones sociorreligiosas contemporáneas en Chiapas, se han modificado diversas prácticas de la Mayordomía y Priostería de Tuxtla que repercuten en el culto a San Pascual Bailón. Para ello, en la investigación se presentan los pormenores del origen del culto a San Pascualito hasta nuestros días. Asimismo, se expone la etnografía de la fiesta patronal, donde se distingue, la forma en que el pueblo vive la devoción a San Pascualito y la manera en la que se conjugan diversas expresiones religiosas.

Palabras clave: religiosidad popular; sincretismo; hibridación; San Pascual Bailón.

\section{ABSTRACT}

This is a religious study that deals with the popular religiosity that occurs around the cult of San Pascual Bailon in Tuxtla Gutiérrez, Chiapas, Mexico. The particularity of this saint is that his representation is a wooden skeleton dressed in a Franciscan tunic that remains in a cart-coffin, which is venerated by thousands of people in various parts of the State. In this sense, the objective of the work is to describe and analyze how, from the contemporary socio-religious transformations in Chiapas, various practices of the Mayordomia and Priosteria of Tuxtla have been modified that have an impact on the cult of San Pascual Bailon. For this, the investigation presents the details of the origin of the cult of San Pascualito to this day. Likewise, the ethnography of the patronal feast is exposed, where it is distinguished, the way in which the people live the devotion to San Pascualito and the way in which various religious expressions are combined.

Keywords: popular religiosity; syncretism; hybridization; San Pascual Bailon.

1 Universidad Juárez Autónoma de Tabasco. Profesor Investigador de Carrera Titular B Tiempo Completo, División Académica de Ciencias Sociales y Humanidades, Universidad Juárez Autónoma de Tabasco, México. Posdoctor en ciencias antropológicas por la Universidad Autónoma Metropolitana. Posdoctor en estudios sociales por El Colegio de la Frontera Norte. Doctor en antropología por la Universidad Nacional Autónoma de México. Estudioso de las identidades sociales, del fenómeno médico y religioso. Perfil deseable del Programa para el Desarrollo Profesional Docente. Miembro del Sistema Nacional de Investigadores del CONACyT. Correo electrónico: gupalex@live.com.mx

(c) 2021 Revista Multi-Ensayos. 


\section{INTRODUCCIÓN}

En enero de 2015 comencé una estancia posdoctoral en ciencias antropológicas en la Universidad Autónoma Metropolitana-Iztapalapa. Entre las actividades propuestas se contempló hacer un estudio de la Santa Muerte en San Cristóbal de Las Casas, Chiapas. ${ }^{1}$ De esta investigación surgió la figura de San Pascualito, como eje articulador de las nociones preliminares sobre la muerte en Chiapas. Durante 2015, 2016 y 2017 realicé trabajo de campo en Tuxtla Gutiérrez, Chiapas, lugar donde se localiza el templo de San Pascual Bailón, conocido popularmente como San Pascualito. La particularidad de este santo radica en que su representación es un esqueleto de madera ataviado con una túnica franciscana que permanece en un carretón-ataúd, el cual es venerado por miles de personas en diversas latitudes del Estado.

En el transcurso de la investigación me surgió una hipótesis que quiero externar acerca de San Pascualito y la Santa Muerte en México. Pienso que San Pascualito se convirtió en la Santa Muerte en el Distrito Federal, hoy Ciudad México. De acuerdo con Carlos Navarrete (1982), en 1902 hubo una figura de San Pascualito en la Catedral de San Marcos en Tuxtla Gutiérrez, Chiapas. En 1908 esta fue trasladada a la Iglesia del Calvario, la cual se localiza a un costado del Mercado Dr. Rafael Pascacio Gamboa, en el corazón de la capital del Estado de Chiapas. Los comerciantes y las clases menos favorecidas que acudían al mercado comenzaron a ser devotos de la imagen, lo que incrementó su popularidad. Sabemos que el mercado como espacio público ha servido históricamente para el intercambio de todo tipo de productos, entre ellos la cultura. No dudo que, en los viajes que hicieron los comerciantes de Tuxtla Gutiérrez, Chiapas al mercado de la Merced en la Ciudad de México para vender su mercancía, haya habido un personaje, familia o un grupo de individuos que llevó una réplica de San Pascualito a la Merced, donde se socializó entre los comerciantes la imagen de San Pascualito con la imagen de la muerte. Con el paso del tiempo se dejó a San Pascualito, porque no tiene culto en la Ciudad de México y nació la Santa Muerte.

Cabe señalar que es entre los comerciantes del centro histórico de la Ciudad de México (la Merced, la Lagunilla, Tepito, etcétera), donde se tienen los primeros registros y donde se ha popularizado el culto a la Santa Muerte. Asimismo, encontré a la Santa Muerte entre los comerciantes de otras latitudes del país. Recuerdo que en 2006 cuando hice trabajo de campo en Chetumal, Quintana Roo, hallé a la Santa Muerte en unos de mis recorridos por el centro de la ciudad. El altar se localiza en la avenida Belice No. 230, entre Venustiano Carranza y Primo de Verdad, a una cuadra del Mercado Ignacio Manuel Altamirano, conocido como "el mercado viejo". En San Cristóbal de Las Casas, Chiapas, me topé con la Santa Muerte en el Mercado de Los Altos, de ahí surgió la idea para la investigación en 2015. Realizando una etnografía en 2018 en Villahermosa, Tabasco, localicé a la Santa Muerte en el Mercado José María Pino Suárez. Otro elemento que encontré como similitud, es que en un principio la Santa Muerte fue ataviada con una túnica franciscana que suele ir atada en la cintura con un cordón de tres nudos y acompañada de unas sandalias. Esta es la vestimenta del franciscano San Pascual Bailón, del cual nos ocuparemos en este estudio.

1 La Santa Muerte es una representación (imagen, pintura, escultura, etcétera) popular en México que personifica la muerte, la cual es objeto de devoción en diversos espacios y contextos. En las últimas dos décadas, su feligresía ha aumentado considerablemente a lo largo del territorio nacional, a pesar de no ser reconocida como Santa por la Iglesia Católica. Básicamente la devoción a la Santa Muerte es un culto de religiosidad popular que se da en todos los estratos sociales, aunque se manifiesta primordialmente entre la población más vulnerable en México (Gutiérrez, 2015). 
Por ello, el presente trabajo inicia con una descripción de la Mayordomía y Priostería zoque de Tuxtla Gutiérrez, Chiapas, México. Después discurre sobre el origen del culto a San Pascualito hasta nuestros días. Luego se habla acerca de la disputa que tienen las instituciones religiosas que adoran al santo esqueleto en Tuxtla Gutiérrez, Chiapas. Posteriormente se expone la etnografía de la fiesta patronal. Por último, se dan unas reflexiones en torno a la religiosidad popular que se vive en la devoción a San Pascualito, la manera en la que se conjugan diversas expresiones religiosas en el culto, así como la dinámica entre sus actores.

\section{La Mayordomía y Priostería de Tuxtla Gutiérrez, Chiapas}

Desde que los hispánicos fundaron la Nueva España organizaron las celebraciones religiosas a través de sistemas de cargos o mayordomías, las cuales comenzaron a expandirse a finales del siglo XVI en la provincia de Chiapas, aunque su período de apogeo "fue hasta principios del siglo XVII" (Aramoni, 1998, p. 91$)^{2}$

Durante la década de 1820 se establecieron los ayuntamientos constitucionales de la nueva república. En el caso concreto de Tuxtla éste se instaló el 1 de enero de 1821, quedando los indígenas, como grupo, excluido de él, razón por la que mantuvieron su antiguo cabildo, que siguió funcionando hasta 1930, pues sabemos que todavía en ese año cuando tomaba posesión el Ayuntamiento mandaba a llamar a los alcaldes y regidores zoques, quienes eran los encargados de que los "naturales" cumplieran con sus disposiciones y ordenanzas (Aramoni, 1995, p. 23).

Este tipo de organización conjugó formas religiosas y políticas en una sola, pero sus cargos cívico-políticos dejaron de estar vigentes en Tuxtla Gutiérrez a partir de la década de 1930.

Antiguamente, los cargos religiosos y los cívico-políticos estaban íntimamente compenetrados, de modo que podía hablarse de una sola jerarquía cívico-religiosa en los pueblos, pero en la actualidad ambas jurisdicciones se hallan formalmente separadas en virtud del proceso de laicización de la autoridad civil (Giménez, 2013, p. 275).

En México, una de las mayordomías que ha sobrevivido parcialmente a los embates de la sociedad moderna, es la Mayordomía y Priostería de Tuxtla Gutiérrez, en la capital del estado de Chiapas. Sus orígenes se sitúan en la Cofradía del Rosario, fundada en octubre de 1731.

Libro de la Cofradía del Rosario Fundada en este Pueblo de Tuxtla por el señor de la real Corona. Comienza este año de mil, setecientos, y treinta, y uno. Dividido en tres partes, de recibo, gastos y cathalogo de los hermanos, que se asientan en dicha cofradía (Archivo Histórico Diocesano, 1731-1820).

En nuestros días, la organización de dicha Mayordomía y Priostería está conformada por una estructura alineada a través de una serie de cargos que los miembros de la asociación religiosa asumen por períodos 2 La mayordomía, "entendida como un sistema de cargos, con implicaciones en la organización político-religiosa de los pueblos indígenas, con marcadas influencias de origen español e indígena se dio a todo lo largo del período colonial y en todos los pueblos indígenas. Desde luego, se debe pensar en variantes regionales en cuanto a su organización, lo que dio diferentes grados de complejidad a esta institución" (Pérez, 1978, p. 128). 
que van de uno a tres años y están establecidos jerárquicamente de mayor a menor. En ese orden está primero el albacea principal de la hermandad; después se encuentran el $1^{\circ}, 2^{\circ}$ y $3^{\circ}$ ayudante de albacea. Luego están los cargos que tienen el compromiso de custodiar alguna imagen. El primero en encabezar a este grupo es el prioste mayor de la Virgen del Rosario, le siguen los priostes del Santísimo Sacramento, San Pascualito y San Marcos. Posteriormente están los cargos de prioste Copoyita Rosario, $1^{\circ}$ y $2^{\circ}$ mayordomo, $1^{\circ}$ y $2^{\circ}$ madre de espera, Santa Catarina, Doloritas y San Juan. Asimismo, son parte de la Mayordomía y Priostería aquellas personas que de manera voluntaria colaboran dándole sabor, colorido y alegría a las festividades, como son los maestros de música y danza, ramilleteros, sastrelavandero, comideras y ayudantes en general (Ver Diagrama 1$)^{3}$

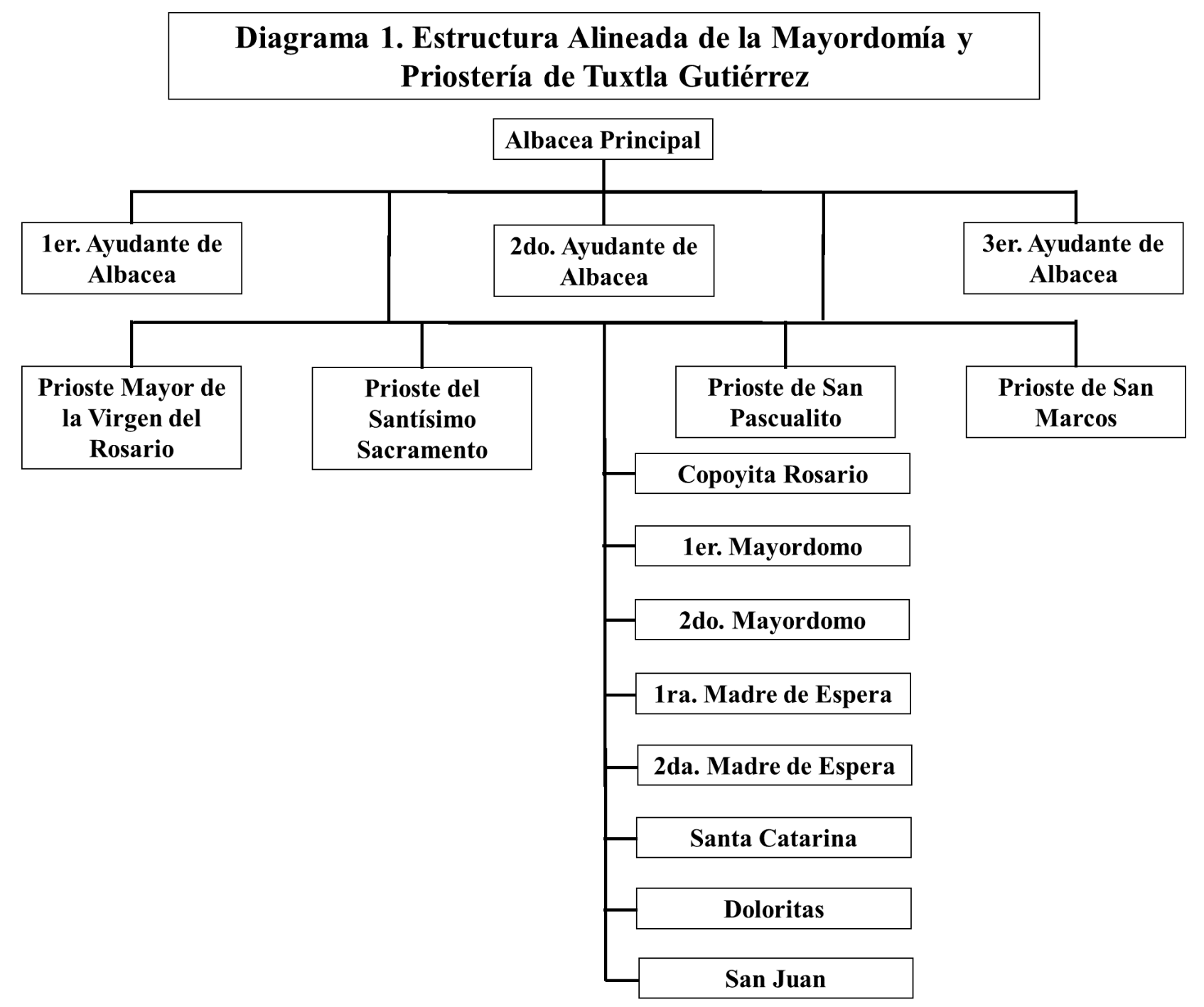

Fuente: Trabajo de campo, 2015.

Como se puede apreciar en el Diagrama 1, uno de los cargos y de las festividades más importantes que tiene anualmente la Mayordomía y Priostería de Tuxtla Gutiérrez es San Pascual Bailón, conocido popularmente como San Pascualito, santo católico del que hablamos en el siguiente apartado.

Entre las singularidades de la Mayordomía y Priostería de Tuxtla Gutiérrez está la forma en que uno accede a un cargo, ya sea por solicitud o por designación del albacea principal. No obstante, el adquirir algún cargo implica todo un proceso y cumple una función específica al interior de la asociación religiosa, 
así como dedicar tiempo y dinero a las actividades ceremoniales de la agrupación. ${ }^{4} \mathrm{Al}$ respecto, Enrique Gómez, actual prioste de San Pascualito nos comenta:

Para tener el cargo de prioste le hice mi solicitud a la Mayordomía. Luego recibí por tres años a unas virgencitas que bajan de aquí de Copoya, esa bajada es un 30 de enero. Copoya es un poblado que está muy cerca y ahí empezó la veneración a la Virgen de María Olaechea, Candelaria y la Virgen del Rosario. Obviamente la Mayordomía te da fecha para que las recibas en tu casa. Desde que llegan las vírgenes hasta que se van, aunque no lo exigen, se hace fiesta, se meten en ramas. Las ramas son un palo de bambú que adornamos con hojas, trastes y frutas. Después buscas a tus madrinas, consigues quema cohete, que los músicos estén tocando todo el día y se da mucha comida. Ese es el primer paso importante si quieres pertenecer a la Mayordomía. Una vez que recibes a las virgencitas, si tu deseo y tus posibilidades te lo permiten, podrás tener una imagen. Entonces el albacea te hace tres visitas para explicarte los compromisos de tu cargo, de qué se trata, qué vas a hacer, y en la tercera visita te pregunta si vas a aceptar el cargo, a pesar de las tres visitas, uno puede decir que no quiere, pero si a ti te nace, ya dices que aceptas el cargo. Aunque el albacea te da la libertad de elegir por cuánto tiempo quieres ser prioste, aquí en Tuxtla tenemos la costumbre de que cuando agarramos una responsabilidad como esta lo hacemos por tres años (Gómez, 14 de mayo de 2015).

Otra de las particularidades de la Mayordomía y Priostería de Tuxtla radica en que el sistema de cargos está integrado por personas que no son de ascendencia zoque, grupo étnico que originalmente conformaba y presidía la hermandad, pero que prácticamente ha desaparecido de la capital de Chiapas. ${ }^{5}$

Yo escuchaba algo que usted le preguntaba a Pepe, cuántos zoques nos quedan en la Mayordomía, ninguno, ya no hay, porque los verdaderos zoques ya murieron (Samuel Ramos, albacea principal de la Mayordomía y Priostería de Tuxtla, 12 de julio de 2015).

De igual forma, es importante mencionar que la finalidad de esta hermandad consistió en organizar a lo largo del año la vida religiosa de los miembros a través del principio de mayordomía, en el sentido estricto de servir a Dios, a los santos y a las vírgenes. ${ }^{6}$ Lo que propiamente es lo que le daba sentido e impulso al engranaje de esta para que continuara funcionando. Sin embargo, en la actualidad la Mayordomía y Priostería de Tuxtla no cumple con dicho propósito, puesto que sus integrantes participan muy poco en

las actividades religiosas que se realizan todo el año, porque viven inmersos en la cotidianidad de una metrópoli, que busca más parecerse a cualquier otra ciudad de México o del mundo.

4 Cuando uno acepta un cargo dependiendo el sexo se les obsequia un regalo que formaliza el compromiso. "Si es mujer se le lleva en una charola cuatro tortas, cuatro rosquillas, cuatro ruedas de chocolate y un kilo de azúcar. Si es hombre se le da un morral que lleva una botella de tequila, una caja de cigarros, igual van cuatro tortas, cuatro rosquillas y un kilo de azúcar" (Ramos, 2015).

5 De acuerdo con el INEGI (2009) en México había 54,004 hablantes de zoque, de los cuales 43,936 vivían en Chiapas y los municipios de esta entidad con más de 1,700 hablantes eran Ocotepec $(8,458)$, Chapultenango $(4,715)$, Francisco León $(3,829)$, Pantepec (3,820), Tecpatán (3,429), Tapalapa $(3,281)$, Jitotol $(2,535)$ y Rayón $(1,788)$. Cabe señalar que "en los municipios de Ocozocoautla y Tuxtla Gutiérrez, algunas localidades son consideradas comunidades de origen zoque, aunque en ninguna de ellas se habla la lengua desde décadas atrás" (Viqueira, 2003; Villasana, 2006, citados en Sánchez y Lazos, 2009, p. 60).

6 Aquellos que servimos a Dios para cuidar, multiplicar y administrar todo lo que el Señor ponga en nuestras manos, porque Dios es el dueño de todas las cosas (Génesis 14:19, Salmos 14:1, 50:1-12, 68:19, 89:11, Hageo 2:8, Corintios 10:26), y nosotros somos mayordomos, responsables que tenemos que rendir cuentas de todo lo que el Señor nos ha dado (Mateo 25:14-30, Lucas 19:1126). Ver Iglesia de Jesucristo de los Santos de los Últimos Días (2009). 
Si comento que no cumple con su propósito la Mayordomía y Priostería de Tuxtla, es porque durante más de un año de trabajo de campo he podido constatar que los miembros de la hermandad están más preocupados por mantener su empleo para sostenerse a sí mismos y a su familia, que por asistir a las festividades religiosas que se realizan todo el año. Se podría inferir que esto obedece, en gran medida, a la situación de crisis social, económica, política, ambiental, etcétera, que se vive nacional e internacionalmente. Aunque otra razón podría corresponder a que, desde hace cuatro décadas, el mundo en el que estamos inmersos se encuentra en una profunda mutación cultural del individuo moderno (Dubet y Martuccelli, 2000; Dubar, 2002; Bajoit, 2003; Touraine, 2005).

Tal cambio en la modernidad ${ }^{7}$ ha implicado que las personas se relajen de los determinismos estructurales, es decir, que los condicionamientos sociales, en todos los campos de la vida social, ya no son tan directos, automáticos, coercitivos, asertivos y exigentes como lo eran antes, ya que las maneras instituidas de pensar, de decir y de hacer, interiorizadas por la socialización, establecen actualmente menos las conductas de la gente (Bajoit, 2008).

Ser sujeto es ser capaz de construir, a lo largo de la vida, relaciones de conocimiento mutuo. Ser sujeto es primordialmente rechazar, tanto para uno mismo como para los demás, las relaciones de dominación, de servidumbre, de autoridad impuesta arbitrariamente, de desprecio y de subordinación personal (Dubar, 2002, p. 252).

Por ello, los individuos contemporáneos apelan cada día más a su autonomía, a elegir, a decidir por sí mismos, a contar con su imaginación, con su iniciativa y con su creatividad. Esta libertad mayúscula, hace que las personas sean "más actores en sus relaciones con los otros, más sujetos en sus relaciones con ellos mismos y, por lo mismo, conducirse más como individuos singulares, y no ya como individuos uniformizados por sus posiciones sociales" (Bajoit, 2008, p. 15).

\section{Historia del culto a San Pascualito en Chiapas, México}

Como punto de referencia he tomado la magnífica obra San Pascualito Rey y el culto a la muerte en Chiapas de Carlos Navarrete $(1982)^{8}$ la cual parte de la hipótesis de Luis Luján (1967) quien plantea que la devoción popular del rey San Pascual en Guatemala podría haber nacido como producto del sincretismo entre una deidad prehispánica relacionada con la Muerte y San Pascual Bailón, personaje del santoral católico.

San Pascual Bailón nació el 17 de mayo de 1540 en Torrehermosa, Zaragoza, España. En 1565 ingresó a la orden franciscana, donde se caracterizó por su vida ejemplar pletórica de bondad y de fe cristiana. Falleció el 17 de mayo de 1592 en Villarreal, Castellón, España. Fue beatificado en 1618 y canonizado en 1690. Se le considera patrono de las obras, asociaciones y congresos eucarísticos, así como también, santifica la cocina y la repostería.

7 Cuando me refiero a la modernidad, estoy hablando de la época contemporánea. Por otra parte, entiendo que la modernidad no es sinónimo de progreso (visión evolucionista de la sociedad), y que precisamente dicha percepción es una limitante en las investigaciones sociales.

8 Cabe aclarar que el territorio que cubre la investigación de Carlos Navarrete (1982) es el de la antigua Capitanía General de Guatemala, por los nexos chiapaneco-guatemaltecos tan íntimos, antes y después de la Colonia. 
En correspondencia a dichas fechas cabe mencionar que hacia 1650 hubo una peste que se identificó como tifo exantemático, el cual asoló parte del centro y occidente de Guatemala "regiones donde la labor misionera estaba encomendada a la orden franciscana, devota del recién beatificado y casi seguidamente canonizado" (Fuentes, 1932; citado en Navarrete, 1982, p. 23).

Sin duda alguna, este hecho trascendió porque de acuerdo con una crónica que recabó el destacado antropólogo guatemalteco:

Sucedió que un indio que se hallaba muy aquejado de la dolencia y ya en los últimos plazos de la vida, en una abstracción, sueño, o letargo, tuvo una visión en que se le presentó un personaje resplandeciente que no supo conocerle, estaba vestido de ropas largas y lucidas de telas que jamás había visto, ni pensado, que le causó mucho recreo y consolación al alma. El indio con la novedad de la visión, se procuró sentar en su pobre lecho y dijo: ¿Quién sois, vos Señor? Y la respuesta fue una como represión diciéndole: ¿Por qué los indios no celebran fiestas a San Pascual Bailón? El enfermo dijo que no sabía que Santo era, ni hasta entonces lo había oído nombrar. A que le fue dicho, que supiese que les sería muy poderoso protector y abogado en sus enfermedades, sí lo invocasen de corazón y le celebrasen, haciéndole imágenes y dedicándole reverentes cultos; porque Dios quería que este santo fuese patrón de los indios para que fuesen libres de la pestilencia que los destruía. Instó el indio diciendo que él desde luego se ofrecía a ser su devoto; pero para que los otros indios lo supiesen, no hallaba modo, porque aunque él lo dijese, no le habían de dar crédito y dirían que estaba sin juicio. Díjole entonces, aquel personaje que le apareciera: No temas, di a todos los indios que en señal de que San Pascual Bailón será su protector, que los libre de la muerte, si se encomiendan a él, tu morirás dentro de nueve días; pero cesará la peste y contagio, y desde hoy no morirá otro de esta dolencia (Navarrete, 1982, p. 28-29).

El indígena llamó a los cofrades de la localidad y les informó la petición del santo, divulgándose en todas las localidades el suceso, lo que dio pie a la propagación del culto religioso. Tanta fue la devoción de algunas comunidades hibridada ${ }^{9}$ con la cosmovisión de la población originaria, que la imagen de la muerte fue asociada con San Pascual Bailón, pero como un ente positivo, convirtiéndose así en San Pascualito Rey, santo de la "buena" muerte.

En cuanto al origen o llegada del culto a tierras chiapanecas, nada se puede decir al respecto, lo que sí se sabe es que a finales del siglo XVIII el santo era conocido cuando menos en San Cristóbal de Las Casas, ya que en la iglesia de San Francisco de Asís hay una pintura en donde están plasmados unos ángeles que llevan la eucaristía, mientras San Salvador de Horta observa cómo levita San Pascual Bailón. Con base en Navarrete (1982) es hasta 1872 que se encuentra la primera alusión documental. Se trata del acta constitutiva de una hermandad dedicada a la veneración de San Pascual Rey, como se le nombra en el escrito:

En la Ciudad de Tuxtla a los cinco días del mes de Diciembre de mil ochocientos setenta y dos, en el Barrio San Jacinto y con asistencia de becinos [de] San Roque y el Santo Calvario, a invitación de los Señores Crisóstomo Sol y Don José Moreno Sospó, se reunieron los asistentes a fin de formalisar una hermandad mayor y tratar sobre los medios posibles para la edificación de una ermita dedicada al culto y beneración 9 Por hibridación se entienden "los procesos socioculturales en los que estructuras o prácticas discretas, que existían en forma separada, se combinan para generar nuevas estructuras, objetos y prácticas" (García Canclini, 1990, p. 3). 
de San Pascual Rey, y después de aber enterado a los concurrentes de los beneficios que la obra acarreará a multiplicar la beneración de la Sagrada Imagen a quien nuestra gente debe fabores y servicios tales en milagros, se prosedió a discutir sobre los pasos para cumplir tal objeto, y no abiendo ostáculo alguno de parte de los presentes se prosedió al nombramiento de dos tesoreros, un secretario para que autorise ingresos y gastos y 3 comisionados para recaudar lo que desde la junta pasada se tiene ofrecido, de parte de algunos vecinos. También se nombró una comisión para entablar platica con el Prioste y Mayordomo naturales que guardan las Reliquias y la Santa Imagen en casa de la Señora Teodora Indilí de Suares para que asistan y se agan representar en la hermandad y colaboren en la construcción de la ermita. Asimismo, se acordó nombrar seis vecinos para que tengan cuidado del trabajo, debiendo cada uno de estos asistir una semana según lista que ellos mismos agan, debiendo dar cuenta de su trabajo ante el secretario nombrado. Resultaron después de la botación electos para los cargos los Ciudadanos Arturo Guillén Chanona, Alfredo Gordillo Sostó, Reynaldo Trujillo, Nicolás Mesté, Felipe Cumbé Ramos y Gumercindo Feliciano. Con lo que concluio la presente Acta que firmaron todos los aquí electos, de que yo, el secretario doy Fé. José Miguel Chanona (Navarrete, 1982, p. 35).

Como se puede apreciar en el acta constitutiva de la hermandad no se menciona el nombre de esta, por lo que suponemos que de acuerdo con los registros que se encontraron en el Archivo Histórico Diocesano de San Cristóbal de Las Casas, y por el culto actual correspondería a la Cofradía del Rosario, hoy Mayordomía y Priostería de Tuxtla. Es posible que el año de 1872 sea la fecha en que fue incorporado el santo a las festividades de dicha asociación religiosa. Sin embargo, como no hay certeza de ello, se deja como una hipótesis.

Lo que ocasiona mucha incertidumbre es que no se sabe si la réplica de San Pascual es la misma que estuvo en la Catedral de San Marcos en 1902 o qué relación pudieran tener, ya que para esa fecha "se guardaba en una de las capillas laterales la imagen de un esqueleto de madera en su carretónataúd, conocido ya con el diminutivo de San Pascualito (...) trasladado en 1908 a la iglesia de El Calvario, creciendo en popularidad entre los comerciantes del mercado" (Navarrete, 1982, p. 36).

En nuestra iglesia, al interior de la congregación hemos considerado que el esqueleto que está dentro del carretón es una réplica de San Pascual Bailón, porque en las guerras carlistas fue saqueado su sepulcro, quemado, redujeron enormemente la propiedad donde vivió, como aquí también pasó en la guerra cristera en México. Muchos ladrones de reliquias saquearon y de lo que se conserva actualmente es el cráneo y mínimo de restos óseos. Hasta donde sé, se hicieron dos réplicas de San Pascual Bailón y la que está aquí en Tuxtla fue traída por frailes franciscanos y depositada en la Catedral de San Marcos, porque de donde nosotros partimos teniendo noticias de la existencia de San Pascual Bailón es de 1902 para acá, que ya se relata que existía un carretón-ataúd con los restos de madera de San Pascual Bailón en el anexo de la Catedral de San Marcos (Rogelio Carrillo Hidalgo, Arzobispo y Patriarca de la iglesia de San Pascual Bailón, 23 de marzo de 2015).

Para 1914 llegaron a Tuxtla las tropas constitucionalistas del General Jesús Agustín Castro, y se dio la orden de destruir la imagen por considerársele idolatría pura. Los indígenas zoques capitaneados por el mayordomo del santo, Antonio Morales, lo sacaron de su capilla y lo fueron a esconder al monte. Se dice que los insurgentes llegaron al extremo de atormentar a los más cercanos devotos de San Pascualito con 
tal de averiguar su paradero, sacrificio que resultó inútil (Navarrete, 1982).

Fue Antonio Morales, un indígena zoque, quien fue el defensor de San Pascual Bailón, lo anduvo escondiendo para que no lo quemaran (Rogelio Carrillo Hidalgo, Arzobispo y Patriarca del templo de San Pascual Bailón, 23 de marzo de 2015).

En 1934 el coronel Victórico Grajales, quien fungía como gobernador de Chiapas, encabezó una campaña anticlerical contra la iglesia católica, persecución religiosa que culminó con el cierre de templos y la quema de santos en las plazas de las principales ciudades del estado: Tuxtla, San Cristóbal, Comitán, Tapachula (Ríos, 2002). Durante ese tiempo la réplica de San Pascualito permaneció oculta.

Luego vino una época en que la imagen permaneció en casas particulares donde se le visitaba en secreto. "Se recuerda un jacal muy humilde cerca de la Cruz Blanca, en los linderos con Terán; luego la casa de doña Nachita en el barrio de Santo Domingo, y después solicitado por la familia de doña Simeona Sol, de por La Lomita, donde estuvo varios años. Finalmente llegó al terreno de una doña Vicenta, quien a sus expensas levantó una sencilla capilla en el traspatio de su casa, en el sitio donde ahora está el templo" (Navarrete, 1982, p. 37).

La devoción del culto a San Pascualito prosiguió creciendo ante el descontento de la iglesia católica oficial: "San Pascualito había sido atacado desde el púlpito por los sacerdotes católicos (...) la práctica de idolatría era la acusación obligada" (Navarrete, 1982, p. 38).

A principios de 1948, la Mayordomía y Priostería zoque de Tuxtla se organizó para hacerle un templo a la osamenta del santo, y alrededor de 1955 lo concluyeron. Sin embargo, la iglesia católica oficial interpuso una serie de denuncias en la oficina federal de Hacienda, sobre los malos manejos en los fondos de este, situación que derivó en la clausura del santuario.

Fueron trascendentales las gestiones de alto nivel ante el presidente de la Cámara de Diputados y de la Secretaria del Patrimonio Nacional en México, para que se reabriera el templo, porque con base en "el acuerdo de libertad de creencias garantizada por la Constitución el culto a San Pascualito tenía razón legal de ser, pero como expresión pública su manejo -control de fondos para la edificación del templo, ganancias por concepto de la feria, limosnas, etcétera- no podía seguir en manos de particulares, sino con garantía de alguna congregación religiosa reconocida" (Navarrete, 1982, p. 42). Este era el principal obstáculo, debido a que ninguna iglesia católica oficial estaba dispuesta a hacerse cargo del recinto si se mantenía la imagen.

El Gobierno Federal Mexicano tuvo que intervenir y el veredicto lo dieron los magistrados de justicia. Como resolución para tomar las riendas del recinto, trajeron a fray Agustín Leonardo García de la Cruz, sacerdote de la Santa Iglesia Ortodoxa Católica Mexicana. La iglesia de San Pascualito reabrió sus puertas en 1960 con el nombre de Catedral Católica Independiente de la Iglesia Romana.

El 11 de mayo de 1959, en vísperas de la festividad de San Pascual Bailón, vino don Agustín y le gustó el 
lugar. En ese entonces quienes resguardaban el templo tenían la costumbre de hacer limpias con albahaca, ellos dijeron que sí, que aceptaban al clero, pero que les respetaran sus rameadas dentro de la iglesia. Encontraron que no se contraponía a la fe, a la predicación del evangelio y ambas partes aceptaron. Así comenzó don Agustín a realizar los trámites de reapertura del lugar y en 1960 se abrió nuevamente el templo. Pero en esos tiempos muchos curanderos, brujos, chamanes, venían a quemar sus velas de todos los colores, traían huevos, gallinas, fotos con alfileres. Por un tiempo se les permitió, pero después se les fue restringiendo poco a poco, hasta que falleció don Agustín Leonardo en 1988. Después lo sustituyó como arzobispo don José León Aguilar y él dio aún más libertades, tanto, que llegaron a tener aquí una imagen de la Santa Muerte, una imagen de Jesús Malverde, venían personas a leer cartas, a quemar incienso, a hacer brujería, esto era un caos, no era el objetivo para lo que fue creada la iglesia. La Secretaria de Gobernación a través de la Oficina de Asuntos Religiosos tuvo conocimiento de todo y hubo varias exhortaciones, con justa razón, para que se quitara, porque podía perder el registro la iglesia, pero él hizo caso omiso de todos los llamados, hasta que en 2010 murió el arzobispo (Rogelio Carrillo Hidalgo, Arzobispo y Patriarca del templo de San Pascual Bailón, 23 de marzo de 2015).

Al fallecer José León Aguilar lo sucedió fray Rogelio Carillo Hidalgo, quien se encargó de arreglar la situación legal de la iglesia en la Dirección General de Asociaciones Religiosas de la Secretaria de Gobernación, registrando el templo como Catedral Católica Apostólica Ortodoxa Independiente Mexicana de Tuxtla Gutiérrez, Chiapas, lugar donde actualmente permanece la réplica de San Pascualito en su carretónataúd. ${ }^{10}$

\section{La disputa por San Pascualito}

Entre las festividades religiosas que actualmente tiene la Mayordomía y Priostería de Tuxtla está la veneración a San Pascualito, actualmente patrono de la Catedral Católica Apostólica Ortodoxa Independiente Mexicana de Tuxtla Gutiérrez, mejor conocida como iglesia de San Pascual Bailón, ubicada en el centro de la ciudad.

Si bien, como ya se relató, en sus inicios la iglesia de San Pascualito era administrada por la Mayordomía y Priostería zoque de Tuxtla, pero al haber un impedimento legal se tuvo que cerrar, dándole las riendas en 1959 a la Santa Iglesia Ortodoxa Católica Mexicana. Desde ese momento, hasta el día de hoy, ha tenido al frente a tres Patriarcas; fray Agustín Leonardo García de la Cruz, fray José León Aguilar y fray Rogelio Carrillo Hidalgo. Los primeros dos permitieron la devoción pública de la muerte dentro del recinto, mientras que el tercero y actual Arzobispo, aunque renovó muchas cosas del templo y del culto, todavía se venera a la muerte, pero de forma privada y muy personal, de hecho, sigue habiendo remanentes de

religiosidad popular al interior de la iglesia, por ejemplo, las rameadas con albahaca, los conjuros, los somes ${ }^{11}$, etcétera.

10 El sonido de una carreta deambulando por las noches en Tuxtla Gutiérrez, es parte de una singular leyenda muy arraigada entre los habitantes de esta ciudad. Se trata de la carreta de San Pascualito, que según dicen, recorre las calles para anunciar a los desahuciados el final de su existencia.

11 "El some es una vara, un palo, que se forra con hojas, a la cual se le cuelgan ofrendas, que bien pueden ser frutas, trastes, ollas o algún otro recuerdo que puede ser de utilidad para el santo. Estos permanecen ocho días y después se recogen para regalar a la gente" (José Lucio Solís, ayudante de albacea, 12 de julio de 2015). 
Había muchas cosas con las que no estaba de acuerdo, y mucha gente no estaba de acuerdo, mucha gente no venía a misa, venía solamente a sus rituales y se retiraban. Cuando falleció don José León Aguilar me hice cargo y fui a la Secretaria de Gobernación, me dieron los lineamientos y me dijeron que respetara los estatutos que hoy nos rigen. Así que empecé a actuar, a limpiar la iglesia de todas esas costumbres, que no es el objetivo principal nuestro, lo de nosotros es evangelizar. Comencé a retirar muchas imágenes, se prohibieron los rituales con veladoras, con huevo, con lociones, todo eso terminó. Mucha gente que es devota de San Pascual Bailón no venía por las costumbres que aquí se realizaban. Conozco personalmente el templo de San Pascual Bailón en España, y es dedicado a la adoración al Santísimo, es un templo expiatorio, este es un templo a San Pascual Bailón y no a San Pascual Rey. Por eso he venido limpiando a la iglesia de todo eso. Ahora tenemos más gente en la misa, es menor la gente que viene por lo costumbrista, vienen por la evangelización, participan en los actos litúrgicos, les gusta más, les atrae más la imagen que presentamos de la iglesia, limpia, bien pintada, con bonitos arreglos florales, mejor atención a los feligreses. Actualmente es una misa tridentina. Cuando estaba el Arzobispo Agustín Leonardo era cien por ciento en latín, excepto con la predica, con el sermón. Con el anterior patriarca [José León], se introdujeron algunas cosas en español. Ahora con su servidor al frente se ha propiciado que haya más participación con la feligresía, por ello hablo más en español, para que la gente intervenga. Siguiendo el rito, primero hablo en latín, tanto en la epístola como en el evangelio, y previo al sermón ya lo hago en español, porque nos interesa evangelizar y que la gente sepa de lo que les estamos hablando (Rogelio Carrillo Hidalgo, Arzobispo y Patriarca del templo de San Pascual Bailón, 23 de marzo de 2015).

Estos cambios ocasionaron una ruptura entre ambas instituciones religiosas, al grado, que fray Carrillo Hidalgo reestructuró la fiesta patronal de la iglesia de San Pascualito -que se realiza del 14 al 17 de mayo-, en donde participaba activamente la Mayordomía y Priostería de Tuxtla Gutiérrez.

Lo que pasa es que el nuevo obispo trae sus ideas. Antes la iglesia de San Pascualito servía tanto para hacer bien como para hacer mal. Nuestra gente, nuestras raíces son de buscar sanación en la curandería, en la medicina tradicional. Nuestros antepasados, los zoques, iban a ese lugar a poner veladoras rojas, negras, blancas, la que tu quisieras, se mantenía a oscuras, se veneraba a la muerte, estuvo la Santa Muerte, y mucha gente a eso iba, a hacer cosa buena como mala, pero cuando llegó el obispo sacó todo eso de ahí, y por eso es que mucha gente se fue de la iglesia de San Pascualito (...) un día hubo una junta allá en el barrio del Niño de Atocha, de todas las personas que conformamos la Mayordomía, en esa junta el obispo quería que participáramos como Mayordomía en el recorrido que hacen por todas las calles de Tuxtla Gutiérrez el 17 de mayo, cuando sacan la imagen en su carretón, pero le hacía ver nuestro albacea [Samuel Ramos] que no podemos participar si se nos limitan nuestra tradiciones (Enrique Gómez, prioste de San Pascualito, 14 de mayo de 2015).

Tal rompimiento también causó que fray Carrillo Hidalgo restringiera a la hermandad en el número de limpias que anualmente le realizaban al santo esqueleto, porque de las cuatro limpias (5 de enero, 14 de mayo, 28 de agosto y 4 de octubre), únicamente les quedaron la del 5 de enero y la del 14 de mayo. Desde 2013, la Mayordomía y Priostería de Tuxtla Gutiérrez celebra por aparte a San Pascualito.

\section{Etnografía de la fiesta patronal}

Aunque hay una ruptura entre las asociaciones religiosas que celebran a San Pascualito en la capital del estado de Chiapas, esto no impidió hacer el trabajo de campo sobre la fiesta patronal, por lo que a 
continuación relato los acontecimientos que presencié.

Durante la noche del 13 de mayo de 2015, fray Rogelio Carrillo Hidalgo, párroco de la iglesia de San Pascual Bailón, y colaboradores de dicho templo, bajaron del altar el carretón-ataúd. Después procedieron a sacar la réplica y la colocaron cuidadosamente en una mesa-altar, cubriendo con una sábana al santo esqueleto.

A las cinco de la mañana del 14 de mayo, los integrantes de la Mayordomía y Priostería de Tuxtla Gutiérrez, comenzaron a congregarse a las afueras de la iglesia de San Pascualito. Con esa parsimonia y falta de prisa que caracteriza a la gente de provincia, el albacea principal, Samuel Ramos, y el prioste de San Pascualito, Enrique Gómez, conversaron en voz baja los últimos detalles organizativos para proceder a la limpia de la sacra osamenta.

Los preparativos empezaron, en realidad, varias semanas atrás, cuando los mayordomos y priostes se reunieron con el albacea principal, para recordarle al prioste de San Pascualito lo que debería llevar a la limpia: cuatro velas blancas, algodón, perfume, aceite, flores, una docena de cohetes, una botella de tequila, una cajetilla de cigarros y ropa nueva para vestir al santo.

Eran las cinco con diez minutos de la mañana cuando el Arzobispo y Patriarca del templo de San Pascual dejó entrar a la Mayordomía y Priostería de Tuxtla Gutiérrez. Al son del carrizo y del tambor, en orden de jerarquía, pasaron uno por uno, luego se cerró la puerta del recinto.

Seguidamente el albacea principal se acercó sigilosamente a los pies del santo, los pocos integrantes de la hermandad que asistieron se pararon detrás de él, y este comenzó a rezar en español. Al concluir las oraciones, el albacea principal y el prioste de San Pascualito recogieron la sábana que cubría al santo, luego le quitaron la túnica franciscana que vestía, dejando al descubierto el esqueleto de madera. El prioste de San Pascualito traía un morral de donde sacó una bolsa con algodón, una botella de perfume y otra con aceite. Mientras el albacea principal elegía a seis miembros de la Mayordomía y Priostería, para limpiar la réplica. La primera de las limpias se hizo con algodón seco y en la segunda el algodón se humedeció con aceite. Después, se procedió a vestir al santo con su nuevo hábito franciscano, luego fue tapado con la sábana que le habían quitado al principio del ritual. Posteriormente el prioste de San Pascualito colocó las flores en un par de jarrones. Por último, encendió los cuatro cirios, uno en cada esquina de la mesa-altar.

Siendo las seis y media de la mañana, se escuchó un estallido de cohetes que anunció el inicio de las festividades patronales que concluirían tres días después, el 17 de mayo, fecha de nacimiento y defunción de San Pascual Bailón. Los integrantes de la Mayordomía y Priostería, con pasos lentos y acompasados, se dirigieron a la salida de la iglesia. Estando afuera del recinto, fray Rogelio Carrillo Hidalgo los invitó a desayunar, por lo que se dirigieron a la puerta contigua del inmueble e ingresaron al patio, en donde había una gran mesa con cuarenta sillas. El Obispo ocupaba la silla central de la cabecera norte de la mesa y alrededor de esta se sentó la Mayordomía y Priostería de Tuxtla Gutiérrez. El desayuno consistió en tamales de bola y pan regional, acompañado de un champurrado de arroz. Los integrantes de la hermandad procedieron a retirarse del templo a las ocho de la mañana, hora en la que concluyó el 
convivio. De los quince integrantes que asistieron, ocho se fueron porque tenían que trabajar, entre ellos el albacea mayor, mientras que los restantes se dirigieron con el sastre lavandero a la casa del prioste de San Pascualito, para lavar la ropa que le acababan de quitar al santo.

Al mismo tiempo que se retiraban los miembros de la Mayordomía y Priostería de Tuxtla Gutiérrez, fray Rogelio Carrillo Hidalgo instruía a sus colaboradores para que procedieran a abrir las puertas del templo. En las inmediaciones del recinto había un poco de gente que esperaba ansiosa el momento para pasar a venerar al santo huesudo. Si bien, son días de fiesta, también son de guardar, puesto que es el único día del año en que está expuesto al público el esqueleto de San Pascual Bailón, lo que ocasiona que mucha gente se reúna a orar en el templo. En el transcurso del día, prosiguieron llegando a la iglesia de San Pascual feligreses de todas las clases sociales, unos con mayor tiempo de estadía que otros, pero sin duda con una gran devoción al santo esqueleto. La mayoría de los fieles compraban su albahaca para su tradicional rameada, aunque algunos otros preferían que les hicieran un su conjuro ${ }^{12}$ (Ver Imagen 1).

\section{Imagen 1. San Pascual en el atrio de su templo}

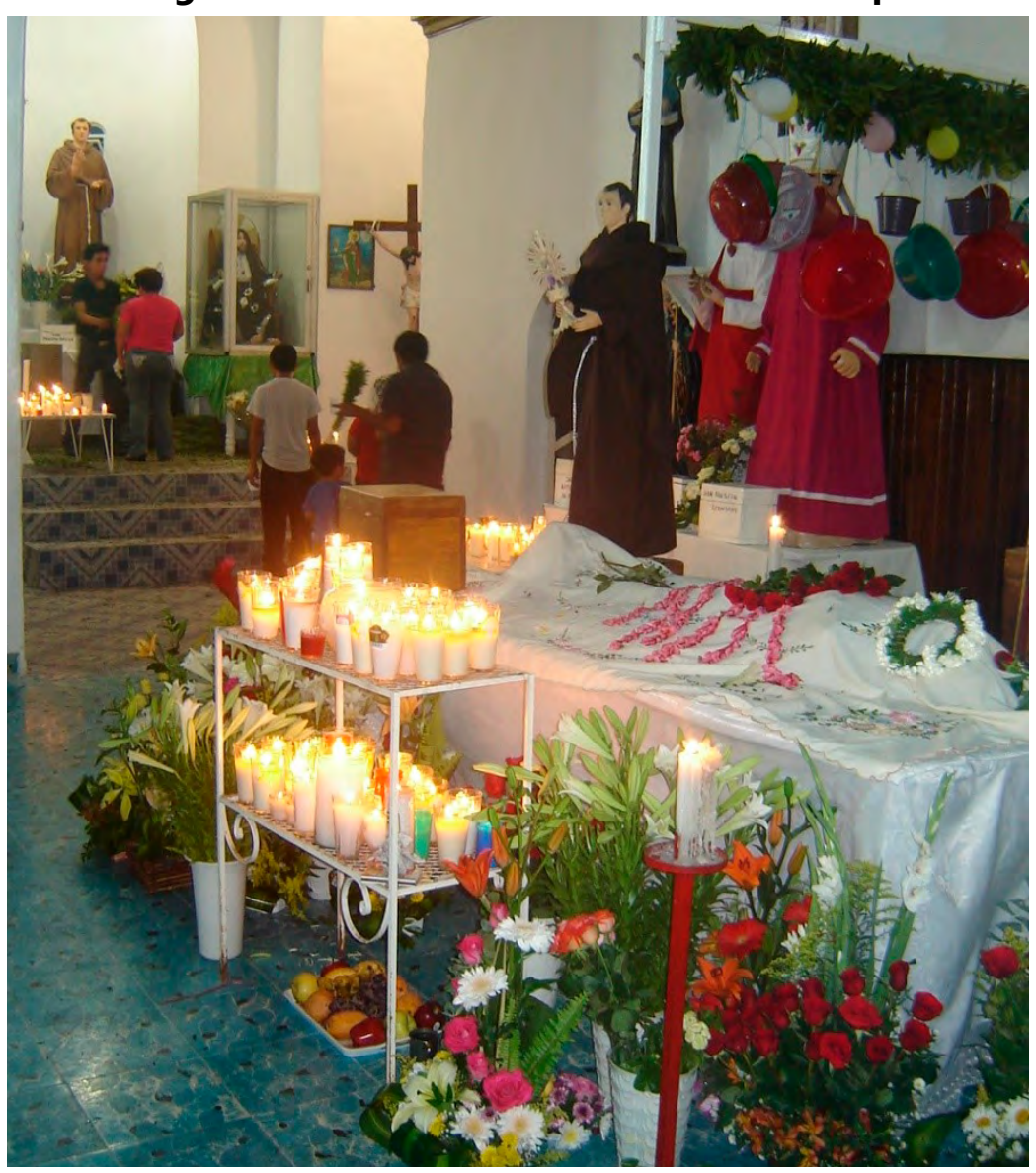

Fuente: Trabajo de campo, 2015.

Por su parte, como al medio día, la hermandad había cumplido con el cometido. La túnica de San Pascualito se encontraba limpia y bien planchada. Como el sastre lavandero tenía pocos días de haber recibido el cargo, aprovechó para hacer el inventario de las pertenencias de San Pascual que se resguardan en un baúl.

Nosotros como Mayordomía hacemos la limpia del esqueleto, le ponemos su ropa nueva y nos retiramos. 
La ropa que se quita, se trae aquí a mi casa a lavar, pero eso lo hace el maestro sastre lavandero. Ya que está seca la ropa se plancha, se dobla y me la entregan, porque mi responsabilidad como prioste es custodiar todas las pertenencias de San Pascualito que están en su baúl (Enrique Gómez, prioste de San Pascualito, 14 de mayo de 2015).

Después el prioste de San Pascualito ofreció -a las diez personas que asistimos-, unas viandas -caldo de pollo, tamales de camarón, cueritos de puerco, pozol de masa, horchata de arroz, cuadritos de piloncillo, etcétera-, que fueron amenizadas con música de jarana y guitarra. Finalmente, en punto de las cinco de la tarde, en el altar que minuciosamente elaboró en su aposento el prioste de San Pascualito, inició el Santo Rosario, actividad con la que concluyó la celebración por parte de la Mayordomía y Priostería de Tuxtla Gutiérrez.

Mientras tanto, en la iglesia de San Pascual Bailón se preparaba el escenario en la calle contigua, para que en punto de las 20 horas iniciará la coronación de la reina de la feria. Todo estaba listo, cuando de pronto subió al templete un payaso, quien fungió como moderador del evento. En primer lugar, presentó a los invitados, luego agradeció a los presentes su asistencia, a los cuales pidió un aplauso para fray Rogelio Carrillo Hidalgo, por haber organizado un año más la fiesta patronal. Después el maestro de ceremonia le dio el micrófono a fray Carrillo Hidalgo, este pidió que subieran la reina entrante y saliente. Dos chicas se levantaron de sus asientos y ascendieron al estrado. Las porras para una y otra eran estruendosas, la multitud no dejaba de gritar. En unos minutos Alejandra primera, sucedió a lleana primera, acto con el que concluyó el primer día de festejos.

El viernes 15 de mayo se abrió la iglesia a las 6 de la mañana. La réplica de San Pascual Bailón ya no estaba expuesta al público, durante la noche fray Carrillo Hidalgo y colaboradores habían guardado en su ataúd el santo esqueleto.

Durante el transcurso del día, muchos feligreses llegaron con flores, somes y velas. Siendo las 17 horas inició el Santo Rosario. Luego a las 19 horas se realizó una misa. Al término de esta, ingresó una peregrinación procedente de Zinacantán, municipio de Los Altos de Chiapas. Minutos después entró otra peregrinación procedente de Villaflores, municipio de la región Frailesca de Chiapas, la cual venía acompañada de unos mariachis que tocaron por 40 minutos. El templo cerró sus puertas a las 22 horas.

El sábado 16 de mayo comenzaron las actividades a las 9 de la mañana con la participación de artesanos que elaboraron joyonaqués (ramilletes) ${ }^{13}$ con los que adornaron el altar del templo y la carreta del santo patrón. Al igual que un día anterior, los devotos ofrendaron somes, flores y velas. A las 17 horas inició el

Santo Rosario. Luego a las 19 horas se realizó una misa para todos aquellos que festejan su cumpleaños en esas fechas y en honor a San Pascual Bailón, evento religioso con el que terminó el día.

El momento cumbre de la fiesta patronal había llegado. El domingo 17 de mayo iniciaron a las 5 de la madrugada las actividades litúrgicas con las mañanitas. Para esto el ataúd con la réplica de San Pascual Bailón estaba en el atrio del templo lleno de flores, la iglesia estaba a reventar, no cabía un alma más, el 13 Los ramilletes son arreglos florales que forman parte de los rituales zoques. Los señores dedicados a hacer ramilletes se llaman ramilleteros. Como ya se comentó en la Mayordomía y Priostería de Tuxtla hay un cargo de maestro ramilletero. 
calor era sofocante, puesto que no hay mucha ventilación en el lugar.

En punto de las 9 horas comenzó la misa en honor a San Pascualito, al finalizar la ceremonia la gente se abalanzó sobre el féretro, con sus ramos de albahaca -los cuales pasaban por encima del ataúd-, se rameaban entre ellos, rameaban a sus familiares, a sus enfermos, lloraban delante del santo esqueleto, parecían inconsolables, afligidos, en eso llegó fray Rogelio Carrillo Hidalgo con una comitiva de señores que levantaron el ataúd, lo sacaron del templo y lo pusieron en su carreta.

Eran las 11 y minutos de la mañana, cuando los cientos de feligreses comenzaron la peregrinación por las calles céntricas de Tuxtla Gutiérrez. Cuando llegamos al panteón municipal -lugar donde se hizo un descanso de media hora- la gente estaba muy cansada, pero no renunciaban a seguir jalando la carreta. Esta fue empujada durante poco más de cuatro horas por mujeres y hombres que se intercambiaron de posición dependiendo de su fatiga y de la penitencia. Los devotos en su mayoría fueron acompaños de familiares y amigos, algunos llevaban a sus críos vestidos de San Pascual Bailón, por lo que la túnica franciscana para esas creaturas, más que un honor fue un martirio, puesto que durante el recorrido hubo más de 40 grados de calor (Ver Imagen 2).

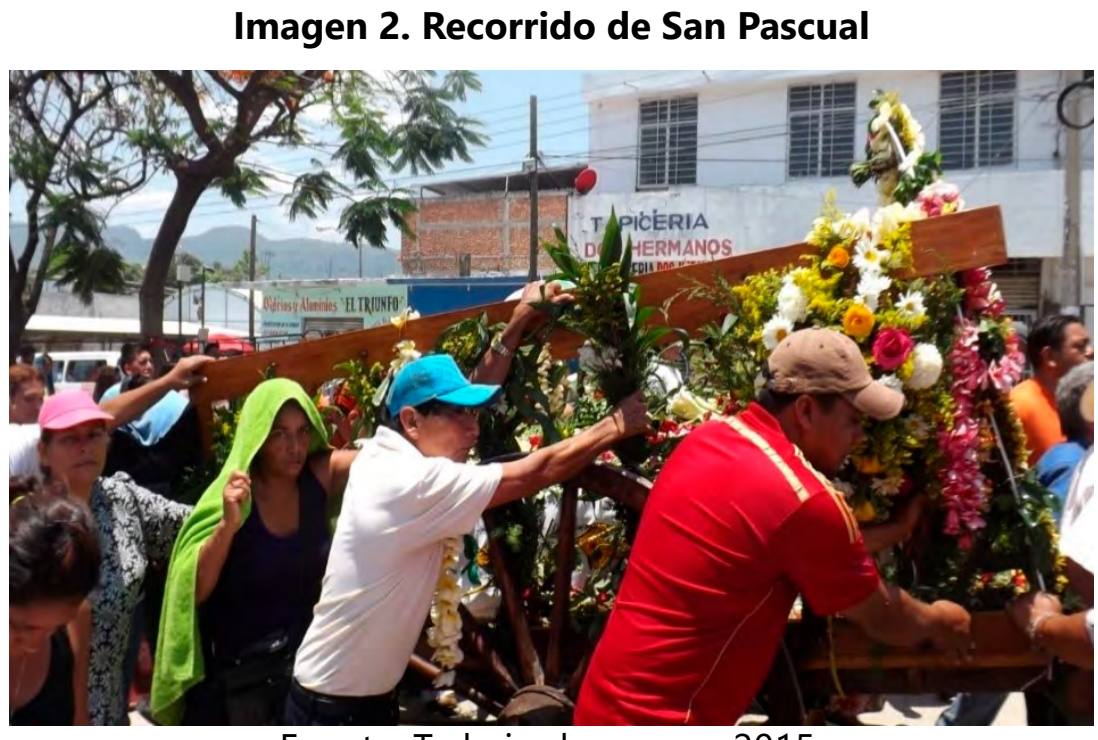

Fuente: Trabajo de campo, 2015.

En la procesión participaron los danzantes denominados como parachicos, procedentes de Chiapa de Corzo, también varios grupos de bailarines de Tuxtla Gutiérrez, unos traían vestidos regionales, otras máscaras de personajes de cuentos de hadas, de brujas, de payasos diabólicos, de monstruos, todos bailando al son del carrizo y del tambor. Por último, a las 18 horas inició el Santo Rosario, ritual con el que finalizó la fiesta patronal 2015 (Ver Imagen 3).

\section{Imagen 3. Recorrido de San Pascual}

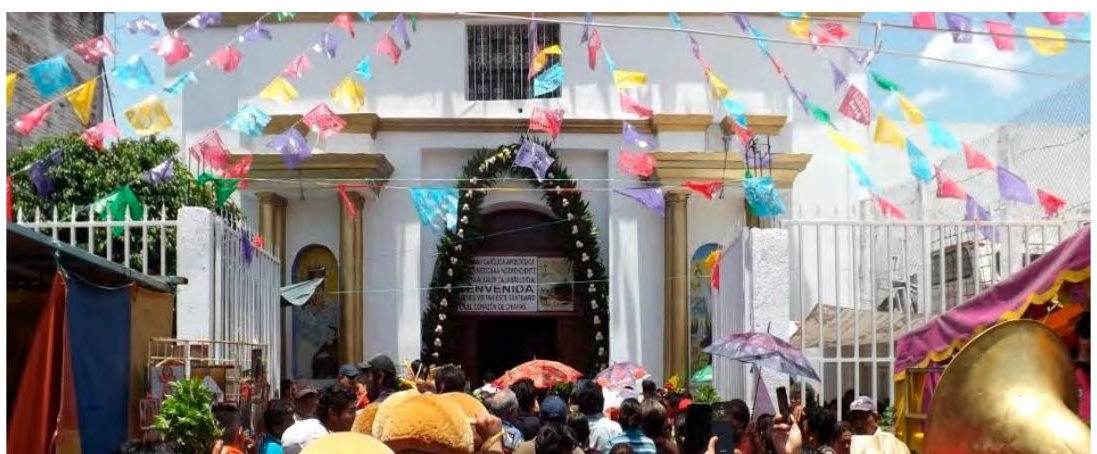


Fuente: Trabajo de campo, 2015.

\section{REFLEXIONES FINALES}

La religiosidad popular enmarca la forma como vive y celebra la religión el pueblo, es la fe practicada y la expresión profunda de la identidad de cultura popular. No es la fe de las grandes doctrinas ni dogmas, la religiosidad popular tampoco es la religiosidad conceptualizada por las elites o por las jerarquías eclesiásticas, es ante todo una práctica, una experiencia religiosa que vive la gente y que ofrece sentido e identidad a su existencia.

La religiosidad popular es la religión de las mayorías, que se contrapone a la de las minorías tanto oficiales (el clero, los religiosos y demás elites eclesiásticas institucionales) como no oficiales (los grupos laicos más próximos al clero) (Marzal, 1973, p. 20).

Una de las particularidades de la religiosidad popular es que pueden encontrarse supersticiones y amalgamas de otras religiones, así como resabios de otras culturas como pueden ser mesoamericanas, afromexicanas, hindús y hasta de rasgos chamánicos. Como muy bien lo apunta De la Torre (2012) "es en la religiosidad popular donde se genera la síntesis entre varios sistemas religiosos: las cosmovisiones indígenas, la magia, el new age. Es en estas porosidades donde se están generando nuevas formas de practicar la religiosidad contemporánea" (p. 14).

En México, la manera en cómo se festeja a la Virgen de Guadalupe es un buen ejemplo de la experiencia de fe popular (Gutiérrez, 2015). Otro ejemplo de imbricación de diversas creencias en el país es el culto a San Pascualito, en la capital del estado de Chiapas.

Respecto a dicha devoción, cabe mencionar que es un fenómeno social ancestral en la región, el cual se nutre de amplios sectores populares de la población, concentrando un extenso sincretismo religioso que entreteje medicina tradicional con diversos tipos de catolicismo y claros matices de New Age o de la Nueva Era. ${ }^{14}$

Como muestra de ello, es que los feligreses continúan con sus "tradicionales" rameadas ${ }^{15}$ (limpias) con

14 Con base en Cristina Gutiérrez (1996) el movimiento New Age o de la Nueva Era "representa sólo una porción de los denominados Nuevos Movimientos Religiosos, cuya aparición ha sido registrada por numerosos autores de Europa y Norteamérica a partir del término de la Segunda Guerra Mundial. Esta aparición ha sido caracterizada por asociarse a cambios sociales rápidos, propagarse velozmente utilizando los avances mercadotécnicos, tener estructuras organizacionales transnacionales, y poseer contenidos doctrinales deliberadamente sincréticos" (p. 90). Gutiérrez señala en el mismo artículo que la Nueva Era "más que un grupo religioso, es una red de movimientos espirituales que comparten ciertos principios, objetivos y formas de acción, pero que se diferencian en otros. Sus conocimientos o base doctrinal, aun cuando tenga orígenes ancestrales, no está definida. Podría caracterizarse como una amalgama de sabidurías y tradiciones pertenecientes tanto a las religiones orientales como a la espiritualidad alternativa o no institucional de Occidente, enriquecida por el discurso científico que una clase media y media alta aprende en el sistema escolar y universitario, y reinterpretada a la luz de la problemática urbana contemporánea. Esta amalgama se crea y disemina en forma no institucional a partir de cursos y talleres de fin de semana, programas de televisión, conferencias de "canales" o channells de maestros ascendidos, promotores de la autosuperación personal o contactados extraterrestres, así como en libros ahora disponibles en los anaqueles de supermercados y anteriormente guardados como esotéricos. hacen explícito que en los grupos identificados con tendencias New Age se puede encontrar todo tipo de gente (p. 91).

15 En el Diccionario Enciclopédico de la Medicina Tradicional que escribieron Mata Pinzón y Zolla (1994) ramear significa "golpear 
albahaca para alejar las malas "vibras", práctica que se ha socializado entre los creyentes como parte de una "costumbre" zoque. ${ }^{16}$

Soy rameador desde hace tres años, no nada más aquí en San Pascualito, también con las vírgenes de Copoya, porque allá también hago esto. Para las rameadas se manejan dos tipos de albahacas y hojas de paraíso, con ellas se recorre todo el cuerpo para limpiarlo de las malas vibras, de las malas energías y de todo eso (Jesús Castillo, 17 de mayo de 2015).

De acuerdo con Guttman (2012) las rameadas sirven para "desechar" algo que ya no sirve, sacar aquello que no hace falta y poder dar paso a todo aquello que es "nuevo" y "positivo". Pueden ser usadas como protección, para atraer las buenas vibraciones, el amor, el dinero, el trabajo, para alejar envidias y sobre todo para deshacernos de maleficios y hechizos.

En ese sentido, podemos decir que se transformó la práctica más no el significado que emplearon durante años los feligreses indígenas zoques al interior del templo de San Pascualito, puesto que las limpias las utilizaron para curar diferentes enfermedades, entre las que destacaron las concernientes a la penetración de inmundicias en el cuerpo, a saber: la contaminación producida por los aires -entes invisibles, con volición o sin ella, que circulan en el viento (aire y mal aire); la brujería, especialmente aquélla donde el hechicero envía fragmentos de basura que se alojan en el interior de su víctima; las emanaciones perniciosas que trasmiten algunas personas a sus semejantes (envidia y mal de ojo); y la acumulación de calor e impurezas durante el embarazo. De igual forma, se realiza para curar los malestares ocasionados por la pérdida de un soplo anímico (pérdida del alma y susto) (Mata Pinzón y Zolla, 1994).

Asimismo, cabe mencionar que, si bien el templo de San Pascualito es católico ortodoxo, en su mayoría la feligresía es católica romana, situación que no afecta en nada la devoción que se le tiene al santo esqueleto. Supongo que esto obedece a que en su raíz San Pascual Bailón sigue siendo un santo franciscano de la iglesia católica romana, además, los creyentes todavía no diferencian entre una doctrina y otra. Como muestra de ello, durante el trabajo de campo realizado en la iglesia de San Pascualito, nunca he presenciado un bautizo, confirmación, boda, graduación, quince años, etcétera, pero me di a la tarea de indagar a la gente que acude a dicho templo, para preguntarles en dónde hacen sus servicios religiosos, la respuesta general fue en la iglesia católica romana. Contexto que es de llamar la atención, porque es muy probable, por una parte, que continúe estando presente en los creyentes, la representación de la muerte a través de San Pascual Bailón, razón por la que no efectúan servicio religioso alguno en dicho templo ortodoxo, y por la otra, es que los devotos prosiguen realizando sus servicios religiosos en la iglesia católica romana, porque tal doctrina religiosa es la que legitima a estos. Lo que nos permite deducir que la iglesia católica romana sigue gozando de un prestigio social entre la feligresía capitalina del estado de Chiapas.

diferentes partes del cuerpo con manojos de plantas". Se practica generalmente como parte de la limpia, o dentro del baño de temazcal. Recibe diferentes nombres según la región donde se utilice y las particularidades en su aplicación.

16 "México, después de Perú, es el país con el mayor número de población indígena en América. Esta nación sobresale por su gran diversidad étnica que se disemina a lo largo y ancho del territorio nacional, ya que no se trata de un grupo de población homogéneo, porque se hablan 11 familias lingüísticas y 68 agrupaciones lingüísticas, las cuales se subdividen en 364 variantes lingüísticas" (Como se cita en Gutiérrez, 2019, p. 673). 
Por último, es importante mencionar que en nuestros días la veneración al santo esqueleto vislumbra una dinámica propia, independiente en su proceso y en sus actores, la cual tiene dos vertientes muy claras. Por un lado, está la representatividad del templo a través del Arzobispo y Patriarca fray Rogelio Carrillo Hidalgo, quien pretende cumplir con el mandamiento cristiano que propiamente es el de evangelizar. Por otro, se encuentra la Mayordomía y Priostería de Tuxtla Gutiérrez, la cual persiste -de manera parcial-con el culto a San Pascualito al margen de la iglesia como institución.

\section{REFERENCIAS}

Aramoni, D. (1998). Las cofradías zoques: espacio de resistencia. VII Anuario. Instituto de Estudios Indígenas (pp. 89-104). México: Universidad Autónoma de Chiapas.

Aramoni, D. (1995). Indios y cofradías. Los zoques de Tuxtla. V Anuario. Instituto de Estudios Indígenas (pp. 13-26). México: Universidad Autónoma de Chiapas.

Archivo Histórico Diocesano (1731-1820). Catálogo Fondo Parroquial. Cofradía del Rosario, Caja 388, Libro 3, Serie Cofradías, Año 1731-1820. Archivo Histórico Diocesano, San Cristóbal de Las Casas, Chiapas, México.

Bajoit, G. (2008). La renovación de la sociología contemporánea. Cultura y Representaciones Sociales, 3(5), 9-31. Recuperado de http://www.scielo.org.mx/pdf/crs/v3n5/v3n5a1.pdf

Bajoit, G. (2003). Todo cambia: análisis sociológico del cambio social y cultural en las sociedades contemporáneas. Chile: Ediciones LOM.

De la Torre, R. (2012). Religiosidades nómadas. Creencias y prácticas heterodoxas en Guadalajara. México: Centro de Investigaciones y Estudios Superiores en Antropología Social.

Dubar, C. (2002). La crisis de las identidades: la interacción de una mutación. España: Bellaterra.

Dubet, F. y Martuccelli, D. (2000). En qué sociedad vivimos. Argentina: Losada.

García Canclini, N. (1990). Culturas híbridas. Estrategias para entrar y salir de la modernidad. México: Grijalbo.

Giménez, G. (2013). Cultura popular y religión en el Anáhuac. México: Universidad Autónoma de Aguascalientes.

Gutiérrez, Á. A. (2019). Panorama étnico religioso en México. Ecos Sociales, 7(19), 672-683. Recuperado de https://revistas.ujat.mx/index.php/ecosoc/article/view/3211

Gutiérrez, Á. A. (2015). Etnografía del culto a la Santa Muerte en San Cristóbal de Las Casas, Chiapas. Quehacer Científico en Chiapas, 10(2), 80-90. Recuperado de https://www.dgip.unach.mx/images/ pdf-REVISTA-QUEHACERCIENTIFICO/2015-jul-dic/EtnografiadelcultoalaSantaMuerte.pdf

Gutiérrez, C. (1996). Nuevos movimientos religiosos: el New Age en Guadalajara. Relaciones, 65/66(17), 89-114. Recuperado de https://www.colmich.edu.mx/relaciones25/files/revistas/065-066/ CristinaGutierrezZuniga.pdf

Guttman, A. (2012). Práctica del culto a la Santa Muerte. México: Editores Mexicanos Unidos.

Iglesia de Jesucristo de los Santos de los Últimos Días (2009). Santa Biblia. Antiguo y Nuevo Testamento. Estados Unidos: Iglesia de Jesucristo de los Santos de los Últimos Días.

INEGI (2009). Perfil sociodemográfico de la población que habla lengua indígena. México: Instituto Nacional de Estadística y Geografía.

Lisbona, M. (2006). Existe una cultura zoque. El concepto de cultura en el marco del debate contemporáneo. Presencia zoque. Una aproximación multidisciplinaria (pp. 19-36). México: UNICACH, UNACH, 


\section{UNAM.}

Marzal, M. (1973). Investigaciones e hipótesis sobre la religiosidad popular. Pastoral y Lenguaje, 18, 13-45.

Mata Pinzón, S. y Zolla, C. (1994). Diccionario enciclopédico de la medicina tradicional mexicana. México: Instituto Nacional Indigenista.

Navarrete, C. (1982). San Pascualito Rey y el culto a la muerte en Chiapas. México: Universidad Nacional Autónoma de México.

Pérez, E. (1978). Mayordomías y cofradías del pueblo de Tacuba en el siglo XVIII. Estudios de Historia Novohispana, 6, 119-131. Recuperado de http://www.revistas.unam.mx/index.php/ehn/article/ view/3262/2817

Ríos, J. (2002). Siglo XX. Muerte y resurrección de la Iglesia Católica en Chiapas. México: Universidad Nacional Autónoma de México.

Sánchez, M. y Lazos, E. (2009). Desde dónde y cómo se construye la identidad zoque: la visión presente en dos comunidades de Chiapas. Península, 4(2), 55-79. Recuperado de http://www.revistas.unam. mx/index.php/peninsula/article/view/44395/40116

Touraine, A. (2005). Un nuevo paradigma para comprender el mundo de hoy. España: Paidós. 